\title{
Impak Industri Pelancongan Terhadap Penduduk Kampung Tellian Tengah, Mukah, Sarawak: Satu Kajian Awal
}

\author{
NUR FARAHIN BINTI SHUDIE* \& NICHOLAS GANI
}

Fakulti Sains Sosial dan Kemanusiaan, Universiti Malaysia Sarawak, 94300 Kota Samarahan, Sarawak, Malaysia

*Corresponding author: 96nurfarahin@gmail.com

\begin{abstract}
ABSTRAK
Industri pelancongan merupakan salah salah satu aktiviti ekonomi yang mampu memberi pelbagai impak, baik yang positif mahupun yang negatif, kepada penduduk setempat. Makalah ini membentangkan hasil awalan kajian yang telah dijalankan terhadap impak industri pelancongan masyarakat Melanau di Lamin Dana kepada penduduk setempat yang tinggal di Kampung Tellian Tengah, Mukah. Pengumpulan data untuk kajian ini menggunakan kaedah pemerhatian dan temubual yang telah dijalankan di kalangan penduduk Kampung Tellian Tengah. Data kajian dianalisis secara kualitatif untuk mengenalpasti impak-impak hasil daripada aktiviti pelancongan di Lamin Dana. Hasil analisis awal mendapati impak yang telah dialami oleh penduduk setempat adalah dalam aspek ekonomi, budaya dan kehidupan, serta infrastruktur dan persekitaran.
\end{abstract}

Kata kunci: Impak industri pelancongan, Melanau, Mukah, pelancongan, Sarawak

\begin{abstract}
Tourism is an economic activity that can contributes various impacts (both positive and negative) to local communities. This article presents the preliminary result of a research that was conducted in order to study the impacts of tourism at Lamin Dana on the lives of the local residents at Kampung Tellian Tengah, Mukah. The data for this study was collected using direct observation and interviews, which were conducted among the local residents of Kampung Tellian Tengah. The data were analysed qualitatively in order to identify the impacts from tourism activities at Lamin Dana. The preliminary results show that the impacts experienced by the local residents are in the aspects of economy, culture and life, and infrastructure and environment.
\end{abstract}

Keywords: Impacts of tourism, Melanau, Mukah, Sarawak, tourism

Copyright: This is an open access article distributed under the terms of the CC-BY-NC-SA (Creative Commons Attribution-Non Commercial-Share Alike 4.0 International License) which permits unrestricted use, distribution, and reproduction in any medium, for non-commercial purposes, provided the original work of the author(s) is properly cited.

\section{PENGENALAN}

Pelancongan adalah salah satu industri ekonomi yang utama dan ternyata pesat membangun di negara Malaysia pada hari ini (Hitchcock \& King, 2003). Hal ini juga dilihat berlaku di negeri Sarawak yang mempunyai pelbagai etnik dan budaya yang menjadi tarikan kepada para pelancong tahun demi tahun. Walau bagaimanapun, kajian-kajian lepas telah menunjukkan bahawa industri pelancongan di serata dunia telah membawa kepada pelbagai impak kepada masyarakat setempat (Hassan \& Siddique, 2016). Kajian-kajian terdahulu telah membincangkan impak-impak industri pelancongan ini dari pelbagai sudut. Contohnya, impak kepada pembangunan infrastruktur sesuatu kawasan (Nayomi \& Gnanapala, 2015), impak kepada ekonomi tempatan (Mochechela, 2010; Samad, Shukor \& Mohd. Salleh, 2013), impak kepada kehidupan sosial dan budaya masyarakat setempat (Enemuo \& Oduntan 2012; Jaafar, Paijo, Mohamad \& Ismail, 2016; Mochechela, 2010; Spanou, 2007; Zaidan, 2016; Zhuang, Yao \& LI, 2019), dan impak kepada alam sekitar (Andereck, Valentine, Knopt \& Vogt, 2005; Brunt \& Courtney, 1999; Mason, 2008; Mohd. Salleh, Shukor \& Mohd. Idris, 2017; Sunlu, 2003). Menyedari hal ini, satu kajian telah dijalankan untuk melihat sama ada aktiviti pelancongan turut mendatangkan kesan kepada masyarakat setempat di Sarawak. Dalam makalah ini, fokus diberikan kepada Lamin Dana yang merupakan sebuah tempat pelancongan yang terletak di Kampung Tellian Tengah, Mukah, Sarawak, yang memaparkan budaya masyarakat Melanau sebagai tarikan pelancong. Seterusnya, tujuan kajian 
ini adalah untuk mengkaji impak-impak pembangunan pelancongan di Lamin Dana ini kepada penduduk Kampung Tellian Tengah di Mukah, Sarawak.

\section{DATA DAN METODOLOGI}

Kajian ini dijalankan di Kampung Tellian Tengah, satu perkampungan masyarakat Melanau di Mukah, Sarawak. Kampung Tellian Tengah juga merupakan lokasi di mana terletaknya sebuah pembangunan pelancongan budaya masyarakat Melanau yang dikenali sebagai Lamin Dana. Nama Lamin Dana sendiri bermaksud 'rumah lama' dalam bahasa Melanau, dan bangunannya dibina dalam bentuk rumah tradisional Melanau yang tinggi. Kini Lamin Dana, yang mula beroperasi sekitar tahun 2000, merupakan sebuah tarikan pelancong di kawasan Mukah. Ia merupakan satu pusat kebudayaan yang mempamerkan pelbagai aspek warisan, sejarah dan budaya suku Melanau tradisional, dan juga menawarkan latihan pembuatan seni dan kraf tradisional. Selain daripada itu, Lamin Dana juga menawarkan tempat penginapan untuk pelawat, makanan tradisi masyarakat Melanau, dan aktiviti-aktiviti lawatan untuk melihat kawasan persekitaran.

Pengumpulan data di lapangan dijalankan di lokasi kajian dari 17 Januari 2020 sehingga 20 Januari 2020. Data kajian diperolehi melalui pemerhatian dan temubual. Temubual yang dijalankan adalah berbentuk separa struktur (semi-structured). Disebabkan oleh tempoh kajian yang terhad, temubual yang dijalankan hanya melibatkan 12 orang responden. Responden-responden ini dipilih menggunakan kaedah snowball sampling, iaitu satu kaedah persampelan bukan rawak, di mana pengkaji mendapatkan responden-responden hasil daripada cadangan daripada responden yang terdahulu. Responden-responden utama dalam kajian ini merupakan Ketua Kampung Tellian Tengah (Encik Boneventure Juana Lupieh) dan pengurus Lamin Dana (Puan Andrea Binti James). Manakala, 10 orang responden lagi terdiri daripada penduduk kampung yang berlatarbelakangkan pekerjaan yang berbeza seperti suri rumah (4 orang), pesara kerajaan ( 2 orang), peniaga kedai makan (2 orang), petani (1 orang), dan pemandu kenderaan awam (1 orang). Daripada 12 orang responden, 7 orang merupakan lelaki, manakala 5 orang adalah wanita. Kesemua responden, seperti kebanyakan penduduk Kampung Tellian Tengah, beragama Kristian.

\section{DAPATAN KAJIAN}

Kajian ini mendapati beberapa impak yang diterima oleh penduduk setempat hasil daripada industri pelancongan di Lamin Dana. Impak yang paling utama adalah impak kepada ekonomi tempatan. Selain daripada itu, terdapat juga impak kepada budaya dan kehidupan sosial, serta impak kepada infrastruktur dan persekitaran.

\section{Impak kepada ekonomi}

Hasil kajian mendapati impak ekonomi utama yang diperolehi akibat daripada industri pelancongan di Lamin Dana ialah industri pelancongan ini telah memberikan peluang pekerjaan kepada penduduk setempat. Antara peluang pekerjaan yang telah wujud akibat daripada aktiviti pelancongan di Lamin Dana adalah penduduk dapat bekerja sebagai pekerja separuh masa (part-time) di Lamin Dana, contohnya sebagai penari tarian tradisional kaum Melanau, sebagai ahli pengurusan protokol majlis yang dianjurkan oleh pihak Lamin Dana dan sebagai pekerja tambahan untuk menguruskan pelancong sekiranya Lamin Dana menerima pelancong yang ramai. Selain itu, aktiviti pelancongan di Lamin Dana juga telah mewujudkan pekerjaan sebagai pemandu bot yang membawa pelancong yang ingin melihat suasana kampung dengan menggunakan jalan sungai (Gambar 1), pembuat kuih tradisional kaum Melanau, pembuat anyaman kraftangan (Gambar 2), dan yang terbaru, pembuat kain Batik Linut (Gambar 3). Golongan suri rumah juga tidak terkecuali dalam mendapat impak yang positif ini. Ini adalah kerana golongan yang bekerja sambilan untuk membuat kuih tradisional dan hasil kraftangan adalah terdiri daripada golongan suri rumah. 


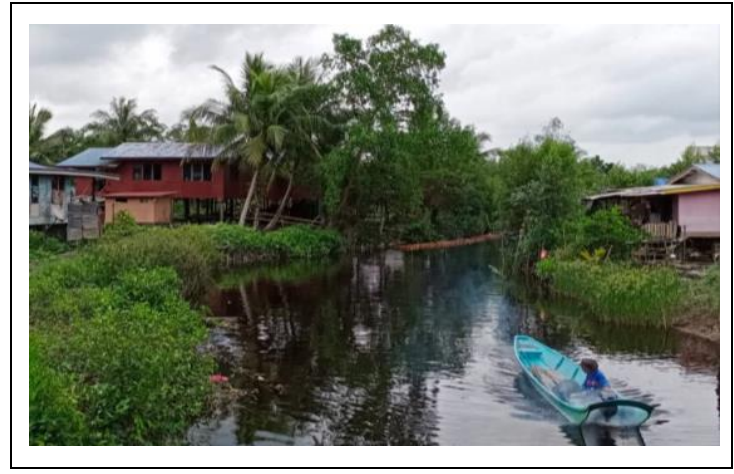

Gambar 1. Salah seorang penduduk kampung yang bekerja sebagai pemandu bot pelancong.

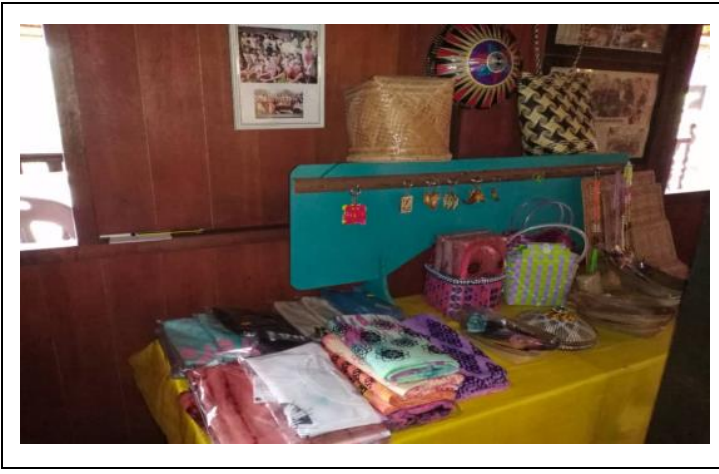

Gambar 2. Barangan kraftangan yang dihasilkan oleh penduduk kampung dijual di Lamin Dana.

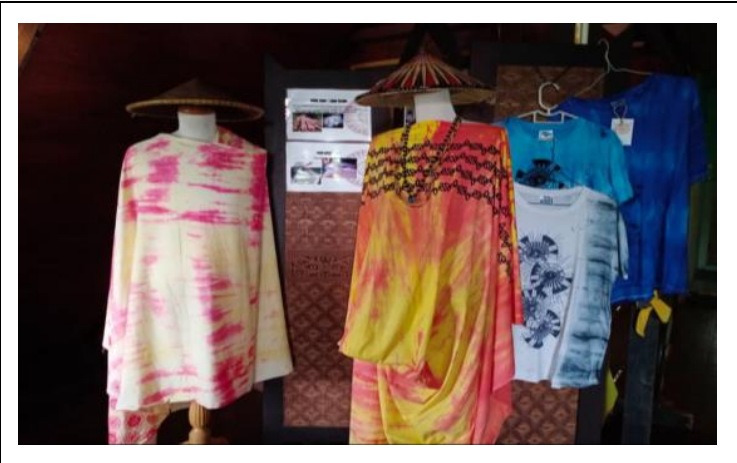

Gambar 3. Batik Linut yang dihasilkan oleh penduduk kampung.

Disebabkan Lamin Dana terkenal sebagai satu tarikan, ia juga pernah dijadikan lokasi penggambaran filem. Ini juga telah memberikan satu punca pekerjaan sambilan kepada penduduk tempatan yang pernah diambil sebagai pelakon tambahan.

Terdapat juga produk ekonomi baru yang diwujudkan oleh penduduk setempat dengan kerjasama pihak pengurusan Lamin Dana. Salah satu contoh adalah kain Batik Linut. Menurut Jamaluddin (2019), memandangkan produk ekonomi utama masyarakat Melanau secara tradisinya adalah sagu, maka sagu juga telah digunakan dalam penghasilan sejenis kain batik yang diberi nama Batik Linut, yang seterusnya telah menjadi produk tradisional yang baru dan unik kepada pelancong yang datang ke Lamin Dana.

Produk ekonomi penduduk setempat juga telah dapat dipasarkan dengan lebih meluas melalui bantuan industri pelancongan di Lamin Dana. Produk ekonomi penduduk setempat semakin dikenali ramai dengan adanya pelancong yang sering datang ke Lamin Dana. Pelancong yang berkunjung ke Lamin Dana ini dikatakan telah mencadangkan kepada orang luar untuk membeli produk ekonomi yang telah dihasilkan oleh penduduk setempat. Misalnya, kuih kering yang merupakan kuih tradisional penduduk setempat pernah ditempah oleh orang luar untuk dijual ke tempat-tempat yang lain. Hal ini demikian kerana kuih kering yang dijual di kampung tersebut hanya berharga RM1.00 sebungkus sekiranya dibeli secara borong. Penawaran harga yang murah ini telah berjaya memasarkan produk ekonomi penduduk kampung secara meluas. Di samping itu, produk ekonomi baharu penduduk kampung iaitu kain Batik Linut juga telah dipasarkan dengan lebih meluas dengan bantuan pemasaran oleh pihak Lamin Dana. Sebagai contohnya, pihak pengurusan Lamin Dana telah menyertai Festival Kraf Tekstil Borneo 2019 yang bertemakan 'Jalinan Inspirasi Kehidupan Borneo', yang telah diadakan di Kota Kinabalu, Sabah (Mohd. Said, 2019). Ia bertujuan untuk memberi peluang terutamanya kepada usahawan kraf tekstil dari Sabah dan Sarawak untuk mempromosikan produk 
mereka. Jadi, walaupun festival kraf tersebut diadakan di Sabah, penglibatan pihak Lamin Dana menunjukkan bahawa mereka telah memanfaatkan peluang yang ada ini untuk memperkenalkan dan seterusnya memasarkan produk baharu seperti kain Batik Linut kepada masyarakat luar.

\title{
Impak kepada budaya dan kehidupan
}

Hasil daripada industri pelancongan di Lamin Dana, budaya masyarakat Melanau telah diberikan pendedahan sehingga ke peringkat antarabangsa. Hal ini dapat dibuktikan melalui kedatangan pelancong-pelancong dari luar negara yang berkunjung ke Lamin Dana pada setiap tahun. Kebanyakannya adalah pelancong dari Eropah yang datang secara berkumpulan bagi merasai kehidupan masyarakat Melanau di Lamin Dana. Pelancong yang kerap datang ke Lamin Dana adalah pelancong yang datang dari Jerman, Belanda, Itali, China, dan Singapura. Kebiasaannya pelancong-pelancong asing ini akan mengambil pakej pelancongan yang telah disediakan oleh pihak Lamin Dana dan mereka kebiasaannya akan bermalam di tempat penginapan yang disediakan di Lamin Dana.

Selain itu, industri pelancongan di Lamin Dana juga telah dilihat mampu menggalakkan pengekalan warisan budaya masyarakat Melanau. Hasil daripada kajian lapangan yang dijalankan menunjukkan bahawa aktiviti pelancongan di Lamin Dana mampu mendorong penduduk setempat untuk mengekalkan budaya yang diwarisi mereka dari generasi terdahulu. Memandangkan Lamin Dana merupakan suatu tempat pelancongan yang memaparkan budaya tradisional masyarakat Melanau, maka ini telah mendorong sesetengah penduduk setempat untuk sentiasa mengamalkan dan seterusnya mengekalkan amalan budaya yang diwarisi daripada nenek moyang mereka. Seperti yang telah dinyatakan oleh salah seorang responden:

Kalau dilihat sekarang ini, memang Lamin Dana ini telah berjayalah dalam mengekalkan budaya nenek moyang kami dulu-dulu. Anak-anak yang tidak tahu sangat dengan budaya dulu-dulu ini boleh tahu sebab adanya Lamin Dana ini. (Responden 7)

\section{Impak kepada infrastruktur dan persekitaran}

Industri pelancongan di Lamin Dana juga telah memberikan impak kepada pembangunan infrastruktur yang terdapat di Kampung Tellian Tengah di mana telah sering berlaku penambahbaikan untuk kemudahan pelancong. Misalnya, kerajaan telah menyumbangkan dana bagi penambahbaikan laluan masuk ke Lamin Dana. Di samping memberi kemudahan infrastruktur kepada pelancong yang datang ke Lamin Dana, penduduk setempat yang tinggal berdekatan dengan kawasan pelancongan tersebut juga telah mendapat kebaikan daripada penambahbaikan infrastruktur yang dilakukan ini (Gambar 4). Perkara ini telah disokong oleh salah seorang responden yang ditemubual:

\begin{abstract}
Ada baiknya juga kalau pelancong guna jalan depan rumah kami ni untuk pergi ke Lamin Dana. Kalau berlaku kerosakan, ada yang akan baiki dan semakin lama orang atasan tengok jalan tersebut tidak sesuai untuk kegunaan pelancong yang nak menuju ke Lamin Dana, dia orang pun simen lah jalan yang di hadapan tu. Kami juga dapat kebaikan daripada situ. (Responden 7)
\end{abstract}

Namun demikian, terdapat isu dari segi penyelenggaraan infrastruktur. Misalnya, terdapat jambatan kayu yang merupakan laluan pelancong ke Lamin Dana Jalan yang kini mengalami kerosakan dan kurang selamat untuk penggunaan harian penduduk tempatan (Gambar 5). Isu kerosakan jambatan ini dikaitkan dengan jumlah pelancong yang ramai yang datang ke Lamin Dana. 


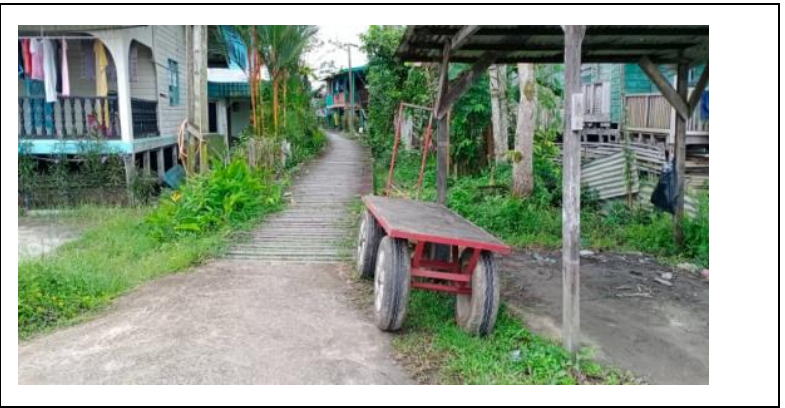

Gambar 4. Laluan masuk ke Lamin Dana yang telah mendapat penambahbaikan untuk kemudahan pelancong

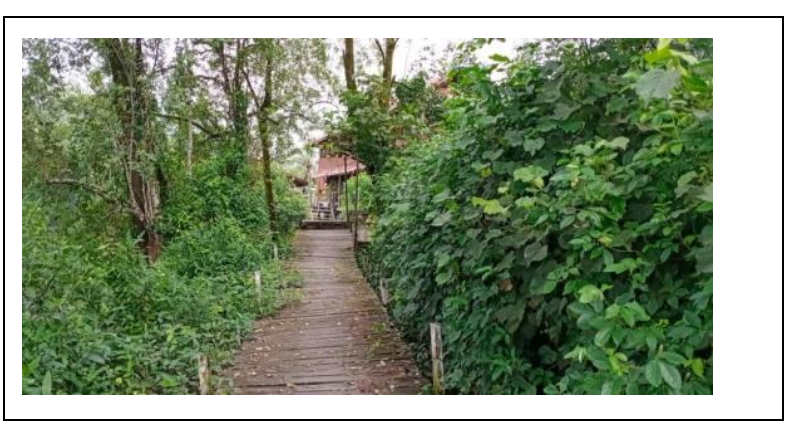

Gambar 5. Keadaan jambatan menuju ke Lamin Dana

Terdapat juga isu pencemaran alam sekitar yang telah timbul daripada aktiviti pelancongan di Lamin Dana. Misalnya, terdapat masalah pembuangan sampah oleh pelawat yang tidak terkawal walaupun kawasan tersebut kebersihannya dijaga oleh pihak pengurusan pelancongan. Perkara ini disokong oleh salah seorang responden yang menyatakan:

Ada juga pelancong yang buang sampah suka hati di sini tapi kami maafkan sajalah sebab kami faham mungkin mereka tidak jumpa tong sampah untuk buang sampah. Ada jugalah yang buang dalam sungai tu. (Responden 3 )

Perkara ini turut disokong oleh pengurus Lamin Dana sendiri yang telah mengaitkan masalah pencemaran sampah kepada sikap dan mentaliti pengunjung tempatan:

Ada juga lah masalah buang sampah sedikit di sini tapi biasanya saya tengok yang banyak buang sampah ni memang orang-orang kita lah, pelancong tempatan biasanya. Kalau pelancong luar ni memang dia orang sangat menghormati tempat sini. (Responden 2)

Dapatan kajian juga mendapati aktiviti pelancongan di Lamin Dana telah memberikan kesukaran kepada penduduk setempat untuk meletakkan kenderaan mereka. Hal ini kerana Lamin Dana tidak menyediakan tempat untuk meletakkan kenderaan kepada pelancong yang datang sehinggakan pelancong yang datang ini meletakkan kenderaan mereka sesuka hati di tempat kediaman penduduk setempat.

\section{KESIMPULAN}

Hasil awalan daripada kajian ini telah menunjukkan pelbagai impak yang telah dialami oleh penduduk Kampung Tellian Tengah, Mukah hasil daripada pembangunan pelancongan di Lamin Dana. Dapatan awal kajian menunjukkan bahawa impak utama industri pelancongan kepada masyarakat Kampung Tellian Tengah adalah impak yang positif di mana pelancongan telah memberikan peluang pekerjaan dan seterusnya sumber pendapatan kepada penduduk tempatan. Hal ini serupa dengan dapatan yang pernah dilaporkan oleh penulispenulis lain yang pernah menjalankan kajian di kalangan masyarakat Kandalama di Sri Lanka (Nayomi \& Ganapala, 2015), di kalangan komuniti Batek di Kuala Tahan, Pahang (Man, Zahari \& Omar, 2009), dan di kalangan masyarakat di Pulau Langkawi (Samad et al., 2013). Selain itu, pembuatan produk baharu dan pemasaran produk tempatan yang lebih meluas juga merupakan impak positif industri pelancongan di Lamin Dana. Tambahan lagi, budaya masyarakat Melanau juga semakin dikenali di peringkat antarabangsa, manakala di peringkat tempatan, telah terjadinya pengekalan warisan budaya. Namun yang demikian, aktiviti pelancongan juga mampu untuk memberi impak yang negatif. Misalnya, Zaidan (2016) mendapati bahawa pelancongan di Dubai telah menyebabkan peningkatan kos barangan dan perkhidmatan, yang seterusnya telah membebankan penduduk tempatan, serta telah meningkatkan kadar jenayah. Di Kampung Tellian Tengah, 
antara impak negatif industri pelancongan adalah dari segi isu penyelenggaraan infrastruktur dan isu pencemaran alam sekitar.

\section{RUJUKAN}

Andereck, K. L., Valentine, K. M., Knopf, R. C., \& Vogt, C. A. (2005). Residents' perceptions of community tourism impacts. Annals of Tourism Research, 32(4), 1056-1076.

Brunt, P., \& Courtney, P. (1999). Host perceptions of sociocultural impacts. Annals of Tourism Research, 26(3), 493-515.

Enemuo, O. B., \& Oduntan, O. C. (2012). Social impact of tourism development on host communities of Osun Oshogbo sacred grove. Journal of Humanities and Social Science, 2(6), 30-35.

Hassan, M. M., \& Siddique, M. Z. R. (2016). Impacts of tourism development on local community: a study on Shalban Vihara. Bangladesh Journal of Tourism, 1(1), 74-82.

Hitchcock, M., \& King, V. T. (2003). Discourses with the past: Tourism and heritage in South-East Asia. Indonesia and the Malay World, 31(89), 3-15.

Jaafar, M., Paijo, M. A. N., Mohamad, D., \& Ismail, M. M. (2016, June). Tourism development and social impact: the case of Mantanani Island, Sabah (Malaysian Borneo). Proceedings of the International Conference on Government and Public Affairs (ICOGPA 2016), Kedah, Malaysia.

Jamaluddin, N. H. (2019). Batik Linut Mukah. Harian Metro. Diambil April 1, 2020, dari https://www.hmetro.com.my/hati/2019/04/444163/batik-linut-mukah

Man, Z., Zahari, N. F., \& Omar, M. (2009). Kesan ekonomi pelancongan terhadap komuniti Batek di Kuala Tahan, Pahang. Jurnal e-Bangi, 4(1), 1-12.

Mason, P. (2008). Tourism impacts, planning and management ( $2^{\text {nd }}$ ed.). Burlington, MA: Butterworth Heinemann.

Mochechela, M. M. (2010). The socio-economic impact of tourism on communities around the Pilanesberg national park, north-west province, South Africa (Unpublished dissertation). University of Limpopo, Mankweng, SA.

Mohd. Said, S. (2019). Potensi Besar Sagu Untuk Hasilkan Batik Linut. Utusan Borneo Online. Diambil Januari 23, 2020, dari https://www.utusanborneo.com.my/2019/04/15/potensi-besar-sagu-untukhasilkan-batik-linut

Mohd. Salleh, N. H., Shukor, M. S., \& Mohd. Idris, S. H. (2017). Impak pembangunan pelancongan ke atas persekitaran manusia dan fizikal komuniti Pulau Tioman. Akademika, 87(3), 47-60.

Nayomi, G., \& Gnanapala, W. K. A. (2015). Socio-economic impacts on local community through tourism development with special reference to heritance Kandalama. Tourism, Leisure and Global Change, 2, 57-72.

Samad, S., Shukor, M. S., \& Mohd. Salleh, N. H. (2013). Impak pembangunan industri pelancongan kepada komuniti di Pulau Langkawi. Prosiding Persidangan Kebangsaan Ekonomi Malaysia ke VIII (pp. $207-$ 216). Bangi, Malaysia: Universiti Kebangsaan Malaysia.

Spanou, E. (2007). The impact of tourism on the sociocultural structure of Cyprus. Tourismos: An International Multidisciplinary Journal of Tourism, 2(1), 145-162.

Sunlu, U. (2003). Environmental impacts of tourism. In G. Camarda \& L. Grassini (Eds.), Local resources and global trades: Environments and agriculture in the Mediterranean region (pp. 263-270). Bari: CIHEAM.

Zaidan, E. (2016). The impact of cultural distance on local residents' perception of tourism development: The case of Dubai in UAE. Tourism: An International Interdisciplinary Journal, 64(1), 109-126.

Zhuang, X., Yao, Y., \& Li, J. (2019). Sociocultural impacts of tourism on residents of world cultural heritage sites in China. Sustainability, 11(3), 1-19. 